\title{
Europa sin politeía, Europa sin política
}

\section{Europe without Politeía, Europe without Politics}

\author{
Jorge Álvarez YÁGÜEZ \\ Universidad Complutense de Madrid \\ jorgealvarezyaguez@edu.xunta.es
}

\section{Resumen}

Se analiza la situación actual de la construcción política europea desde un punto de vista coyuntural y estructural. Se considera que esta situación crítica se enmarca en un proceso de rebasamiento de los Estados nación, sin que, sin embargo, se den aún instancias políticas que puedan asumir funciones parejas a un nivel superior, especialmente en lo que se refiere a la domesticación de los mercados. Esto hace que las tendencias de repliegue o centrífugas se vean con fuerza acrecentada. Se apunta como única posibilidad de salida del actual estancamiento, el reforzamiento de los elementos políticos, apoyándose en los procesos de aprendizaje de abstracción progresiva de los ciudadanos y de los pueblos europeos, lo que solamente si es acompañado por una política social de redistribución, que es lo que hasta ahora representaba simbólicamente Europa, puede tener éxito.

Palabras clave: Estado nación, neoliberalismo, republicanismo, política, démos.

\begin{abstract}
The current situation of European political integration is analyzed from a cyclical and structural point of view. It is considered that this critical situation is part of a process of overcoming of Nation-state, without new political bodies that can take similar functions, at a transnational level, especially in regard to the domestication of markets. This makes the nationalist or centrifugal trends increase its force. It is noted as the only way out of the current impasse, strengthening its political factors, supporting on the learning process, of progressive abstraction, of citizens and of the European peoples, so only if accompanied by a social policy of redistribution, symbol of Europe so far, this can succeed.
\end{abstract}

Keywords: Nation- state, neoliberalism, republicanism, politics, démos. 
1. Cualquier análisis político que hoy se haga está determinado por la situación de crisis del Estado nación y su atribuida soberanía. La transmutación de este espacio es comparable a la que en su momento sucedió respecto al paso de la pólis o civitas a los imperios y Estados. Las categorías políticas se ven cuestionadas al mismo tiempo, como no podía ser de otro modo.

Los Estados nacionales han sido hasta ahora el ámbito preferente y más relevante en que ha podido hacerse realmente política, esto es, autogobierno de la sociedad, capacidad por parte de ésta de modelarse a sí misma. Ha sido, además, el único medio por el que se ha conseguido compensar los efectos indeseables del capitalismo, al menos en los países que han logrado levantar un Estado de bienestar. Hoy lo uno y lo otro están en cuestión, el Estado como el lugar privilegiado de la política, como el medio fundamental de autoconstitución colectiva, y el Estado como herramienta de equilibrio social.

La tradicional concatenación Estado, territorio, pueblo, economía; esta co-pertenencia de los distintos niveles (político, espacial, social, económico), lo que U. Beck llamaría el Estado contenedor ${ }^{1}$, y donde se ha realizado a través de un largo proceso histórico esa figura que es el Estado democrático y social de derecho, se ha desanudado. Los flujos sociales, las fuerte corrientes de inmigración han complejizado la composición de cada démos; hace tiempo que las redes económicas no se cortan por el patrón de los territorios nacionales ni están sujetas a los dictámenes de sus administraciones; las funciones clásicas de los Estados, de paz, seguridad, libertad, y obtención de legitimidad se ven amenazadas por procesos transnacionales de naturaleza diversa: epidemias, terrorismo, crimen organizado, intercambios financieros, amenazas ecológicas. El Estado se ve rebasado y carece de resortes políticos para influir sobre ellos.

Sucede que cuando se había llegado a la domesticación del Leviatán, a su transformación democrática y a su orientación social, una vez que se consiguiera, después de multitud de luchas históricas, poner su poder y alcance en relación con las necesidades de la población, aquel ha quedado demediado, y lo que nos determina se juega en otra parte.

En el control de aquellos procesos que rebasan las soberanías nacionales no se muestran mucho más eficientes los mecanismos asociados a la mera actividad de los Estados como sujetos autonomizados en el plano internacional, los viejos sistemas de alianzas más o menos coyunturales, los clásicos tratados multilaterales, o las organizaciones de intereses tipo G-8, G-20, etc. No parece que baste ya la simple inserción de los Estados en espacios de negociación mundial.

Lo que se dice de los Estados debe aplicarse igualmente a las organizaciones que en ellos operan, partidos, sindicatos, movimientos sociales -se toma aquí el concepto de Estado en un sentido gramsciano, de integración de política y sociedad civil-

${ }^{1}$ U. Beck, What is the Globalization, Cambridge, Polity Press, 2000, p. 23. 
toda vez que la actividad de aquellos, salvo en esporádicas acciones, está referida toda ella al ámbito de los respectivos países, e incluso cuando tratan cuestiones que tienen una envergadura transfonteriza a menudo lo hacen desde la recortada óptica nacional.

Se está, en definitiva, ante una carencia de fondo, en un verdadero fin de época, de cambio estructural en que los medios e instituciones políticas ya no dan alcance a aquellos procesos que determinan nuestras vidas. Se requiere, en consecuencia, de nuevas formas políticas de alcance mayor al delimitado por las naciones, y de movimientos y acciones políticas transnacionales y aún mundiales.

Los ciudadanos se encuentran ante un enorme desafío, en el que el paso hacia un nivel más amplio, transnacional viene exigido por el principio democrático mismo, en la medida en que ya solo en ese nivel tienen la posibilidad de intervenir sobre las fuerzas que han desbordado el ámbito de capacidad del Estado nacional. En ese nuevo marco, al margen de otros problemas de no menos calado, pretenden, cuando menos, conservar lo que por doquier ven que se les escapa, aquellas dos conquistas tenidas en el ámbito nacional: la legitimación democrática del poder y el encauzamiento del capitalismo; que sea lo que fuere que se construyese en ese medio transnacional permitiese conservarlas.

2. Sean cuales fueren los motivos de constitución de la Unión Europea desde sus orígenes a hoy, ha despertado las expectativas de convertirse en una de esa nuevas formaciones políticas de carácter transnacional que pudiera servir a los nuevos desafíos generados. Su conformación apunta a una especie de Federación de Estados europeos. O algo semejante, pues no necesariamente habría de responder a los modelos en que se han conformado los Estados nacionales. Lo que hasta ahora hay no es eso, sin duda. La articulación de sus instituciones Comisión, Consejo y Parlamento, Tribunal europeo, etc. aun sin acogerse a una verdadera Carta Magna, no responden por el momento a tal patrón. Ni el par Consejo-Comisión tiene atribuciones de un gobierno cercano a un tipo federal, ni mucho menos el extraño parlamento europeo, vaciado de poder, cumple las funciones de una cámara de representantes al uso. En la situación actual, posterior a los Tratados de Maastricht (1992) y Lisboa (2007), situación de transición, este entramado institucional se ha quedado a medio camino entre los viejos convenios intergubernamentales y un nuevo tipo de Estado transnacional. Y, como Maquiavelo no dejara de advertir, las situaciones de falta de resolución, que se quedan a mitad de camino son las peores. Por esto, creo que la prudente y bien definida propuesta kantiano-derrideana que avanza cuidadosamente Davide Tarizzo de un espacio de hospitalidad sería hoy escasamente operativa, bien porque resulta insuficiente limitándose a un abierto flujo de las poblaciones con ciertas garantías jurídicas; o bien, cuando va más allá, hacia unas garantías sociales, porque se carecería de la estructura política que pudiera hacerlo efectivo, lo que, por otra parte, exigiría una importante unificación de las economías nacionales a las que la misma 
propuesta se opone. En las condiciones actuales se reduce aceleradamente el margen de acción para todo aquello que no sea capacitar políticamente a la Unión.

Cuando los Estados nacionales han sido rebasados en sus capacidades de intervención, y la nueva construcción transnacional ha coadyuvado a limitar todavía más su ya de por sí reducida soberanía, la falta de operatividad de esta nueva construcción abunda en la incapacidad manifiesta de encauzar los procesos naturalizados. La incapacidad política no hace sino ahondarse. En esta fase paralizante se refuerzan progresivamente las dos posiciones que se resisten a una nueva y verdadera construcción política europea. Los euroescépticos, envueltos aun en la ilusoria idea de un poder nacional, que se estiliza en una visión retrospectiva, se cargan de razón en medio de esta irresolución, exigen medidas proteccionistas, de limitación de los flujos migratorios, especialmente con respecto a los nuevos países miembros, y, en definitiva, la ruptura con la Unión. Más peligrosa, me temo, resulta la posición de lo que se ha dado en denominar europeos de mercado, pues estos se darían por satisfechos con una situación muy parecida a la actual, corregidas sus disfuncionalidades administrativas, $y$, en todo caso, con un organismo que se limitara a dar garantías y seguridad jurídica al libre juego de las fuerzas económico-financieras. Claramente, pues, los partidarios de un avance político, se llamen eurofederalistas o constitucionalistas sin Estado, son los perdedores en todo esto, y con ellos serían derrotadas, una vez más, las capas sociales populares, el bloque social progresista; frustradas las exigencias de ampliación del principio democrático y de ciudadanía.

El problema es que en la parálisis actual todo se abandona a las tareas del día sin ningún proyecto de fondo claro que las oriente. Para más de un funcionalista ese es el modo de avanzar, dejando que la solución de los problemas que surgen y su propio decurso cree la necesidad de una mayor unión y la vaya generando. Sin embargo, sin un plan claro ninguna integración real, no meramente sistémica sino también normativa, puede darse ${ }^{2}$. En la UE, en estos momentos nadie quiere hablar de esto, y nadie sabe, por tanto, hacia donde ha de avanzarse, y las dificultades no hacen sino acumularse. Algunas de éstas son de orden estructural.

Destacaremos cuatro de estas dificultades especialmente relevantes: el tan reconocido déficit democrático en el funcionamiento de las actuales instituciones de la UE, la inexistencia todavía de una esfera pública europea, la falta de una verdadera ciudadanía europea y la débil activación de una cultura política común.

a) No le falta razón al incombustible Perry Anderson ${ }^{3}$ cuando afirma que la expresión déficit democrático tiene una buena dosis de eufemismo, pues el elemento democrático no es precisamente el dominante. En su lugar, Anderson prefiere hablar

\footnotetext{
${ }^{2}$ J. Habermas, El Occidente escindido, trad. de J. L. López, Madrid, Trotta, 2006, pp. 71-72.

${ }^{3}$ P. Anderson, The New Old World, London, Verso, 2009. J. A. Estévez Araujo ha escrito un clarificador artículo con motivo de su reciente traducción al español: "La Unión Europea en perspectiva", en Mientras tanto 118,2012 , pp. 17-37.
} 
de oligarquía con algunos gestos de democracia. Sin llegar necesariamente a este punto, es preciso reconocer que todo lo construido hasta aquí ha sido por élites sin apenas participación de las gentes; que la toma de decisiones en los distintos niveles es absolutamente opaca, lejos no ya de un modelo de democracia deliberativa, sino de la más simplemente convencional; que las grandes instituciones que conforman la UE adolecen de la necesaria legitimidad, alejadas como están de los únicos focos de la misma, anclados aun en los distintos parlamentos nacionales. Es demasiado larga la cadena que une esa fuente con aquellos organismos. El parlamento europeo sigue siendo elegido sin la actuación de partidos o movimientos de alcance europeo, sino de corte nacional, y como institución carece de auténtica iniciativa legislativa, limitándose a enmendar las propuestas que recibe de la Comisión o del Consejo, sin que pueda ejercer control real sobre éstos. Nada que se pueda comparar, pues, a la construcción democrática de los distintos Estados miembros, toda vez que a los ciudadanos todo les viene dado, derechos e imposiciones. Como apunta atinadamente Hauke Brunkhorst: "El déficit democrático de Europa se basa en el hecho de que los ciudadanos tienen derechos, pero no se han dado esos derechos a sí mismos"4. No han participado siquiera en su definición.

Tales condiciones han dejado las manos libres a las élites de los países más poderosos. Si hasta ahora esta situación ha podido mantenerse ha sido por su funcionalidad, porque las gentes y los países menos poderosos han obtenido beneficios, ya en forma de suplementos jurídicos progresivos o en forma de ayudas económicas. Pero la ampliación hacia el Este, con el consiguiente aumento de necesidades frente a un escaso presupuesto -que alarmantemente nunca ha rebasado el 1\% del PIB europeo- unido a la obscena crisis actual to ha cambiado todo, y ha actuado como un revelador de la verdadera situación de la UE, poniendo de manifiesto cómo su realidad responde más a un modelo meramente intergovernmental en vez de a uno de tipo supranational -según la distinción de Brunkhorst-, por lo que se desenvuelve en el contexto de procesos de negociación (bargaining) entre las élites poderosas, frente a los procesos de argumentación (arguing) más propios de la democracia deliberativa que exigiría el segundo modelo ${ }^{5}$. La situación actual se parecería, por tanto, más a la tradicional de las negociaciones entre Estados nacionales en el contexto de las viejas políticas de equilibrio.

Con todo, sería un error creer que todo depende de propuestas de un buen rediseño institucional para alcanzar la vía real para la democratización esperada, pues ésta no depende meramente de factores institucionales, sino sobre todo de la participación de los movimientos sociales, que se verán obligados a tomar iniciativas a contrapelo

\footnotetext{
${ }^{4} \mathrm{H}$. Brunkhorst, "A polity without a state? European constitutionalism betwin evolution and revolution", en Arena Working Paper 14/03, p. 18; editado también en E. O. Eriksen, J. E. Fossen, A. J. Menéndez (eds.), Developing a Constitution for Europe, London, Routledge, 2004.

${ }^{5}$ Ibidem, p. 13
} 
de las instituciones, erigiendo eso que P. Rosanvallon ha llamado con expresión no muy feliz instancias de contra-democracia ${ }^{6}$.

b) Este déficit democrático se acentúa al ir unido a la falta de una esfera pública europea. Nunca podrá haber un sentido de pertenencia a algo común si los medios en que se expresa -y al mismo tiempo se conforma- la opinión pública no se ocupan de manera central de las cuestiones que se debaten en los organismos europeos, de la toma de decisiones, de la repercusión de las medidas en cada país. Y, claro es, si la ocupación en tales temas no se hace desde una óptica meramente nacional, de parte, como suele ser el caso. La formación de opinión y voluntad, esencial para toda vita civile, es decir, democrática no podrá darse mientras esto no exista. Ni siquiera tiene pleno sentido un parlamento que no es vivificado por esa esfera de opinión pública de la que él es a menudo receptor, y sin la que su arraigo legitimatorio quedaría muy debilitado. Es evidente el papel que juegan en ello los intelectuales, y por esto no habría que entender reductivamente el tipo que pudo simbolizar en su momento un Emile Zola, la "conciencia de todos", el representante de lo universal, sino y sobre todo ese otro que Foucault denominaba intellectuel spécifique ${ }^{7}$ que se ocupa en un campo determinado (alimentación, aguas, energía, comunicaciones, aparato judicial, medicina, etc.) y que es capaz de intervenir en el debate público sobre un tema específico y ayudar a conformar una determinada orientación de la colectividad.

En la génesis de esa misma esfera tienen, obviamente, un papel esencial el debate que sean capaz de generar los integrantes destacados de los movimientos sociales, de partidos y sindicatos, las acciones que sean capaces de desencadenar en relación con las cuestiones que afectan a la UE desde una visión globalizante. A este respecto, las manifestaciones masivas de 2003 convocadas a la vez contra la guerra de Irak en las distintas capitales europeas son un ejemplo de esa construcción de la que hablamos. La crisis actual ha apuntado algo en esa misma línea, pero más tímida y confusamente debido a las distintas posiciones que respecto a la misma UE se están generando.

c) Ni que decir tiene que este factor es crucial en la configuración de una ciudadanía europea en un sentido republicano, en el mismo que en negativo apuntábamos antes con la cita de Brunkhorst, esto es en el de participación y no de meros receptores o usuarios de un estatuto jurídico advenido. En realidad, no hay lo uno sin lo otro, una esfera pública europea es sujeto y objeto a la vez de la emergencia de esta

\footnotetext{
${ }^{6}$ É. Balibar ha insistido en este punto, corrigiendo la perspectiva que califica de excesivamente formalista de Habermas. Ver É. Balibar, "What Democratic Europe? A Response to Jürgen Habermas", en Green European Journal 01/10/2012.

${ }^{7}$ M. Foucault, "Entretien, par A. Fontana, P. Pasquino" (1976), en Dits et écrits, t. III., Paris, Gallimard, 1994, pp. 154-155. En ese amplio campo habría que inscribir también acciones intempestivas del tipo de la de los participantes en la organización WikiLeaks, o de los que han revelado torturas en las intervenciones militares internacionales, o las del experto financiero Hervé Falciani dando a conocer a diversos gobiernos listas sensibles de altos evasores fiscales.
} 
ciudadanía, conformadora y expresiva de ella al mismo tiempo. Que esto supone cambios en la misma organización de partidos, sindicatos y movimientos sociales en general no es menos evidente, y es justamente en las organizaciones que se dicen vanguardia por donde tendría que comenzar a darse esto, y lo que vemos es a todas luces insuficiente. No hay más que recordar cómo se han dado las elecciones al parlamento europeo, en que los partidos han actuado primando el enfoque nacional y los intereses domésticos, filtrando todas las cuestiones desde ellos y con la mira puesta fundamentalmente en las consecuencias ad intra. Como apuntaremos enseguida, en cuanto surgen dificultades en la UE se intensifican todos los movimientos a favor del destructor imperio de la particularidad.

d) Concatenado con estos dos elementos, esfera pública y ciudadanía, está un tercero que es transversal a ambos: una cultura política común. La integración jurídica es, ciertamente, Habermas ha insistido en ello, el medio capital en la cohesión de las sociedades complejas modernas, pero ésta por sí sola es inane si no se da unida, si no es vivificada por algo más amplio que se expresa en ese mismo orden de legalidad pero no se agota en él, que es el compartir un conjunto de valores, prácticas, hábitos, formas de expresión del interés por lo público que delimitan el extenso campo de lo que se denomina cultura política ${ }^{8}$.

En este sentido puede decirse, que si hay algo que identifique a Europa, tanto en el imaginario de los diversos pueblos que la conforman como en la percepción de los extra-europeos, es toda una tradición de luchas históricas de lo que Hegel conceptuó en su momento como subjetividad moderna, y que va unida al principio de libertad, y, diríamos nosotros, a la especial estructuración del mismo en el Estado democrático y social de derecho. Los valores de libertad, individualidad, tolerancia, solidaridad, equilibrio social, mas allá de cualquier perspectiva crítica con la que puedan y deban ser abordados, son enseña de eso que más o menos confusamente se llama modelo europeo, como son igualmente rasgos comunes: una confianza mayor en la regulación institucional, una mayor desconfianza hacia el mercado, una vida más marcadamente secularizada, nuestra reticencia a cualquier invasión de lo público por el poder religioso, o el valor positivo dado a la política?

Como puede apreciarse, lo que hoy más claramente identifica a los europeos, ad intra y ad extra, es justamente aquello que puede mantener unida a cualquier sociedad compleja, también en el reducido ámbito nacional, una cultura política que se sitúa por encima de las doctrinas comprehensivas (Rawls), por encima de otros elementos más eticistas como costumbres, lenguas o creencias. La integración que

\footnotetext{
${ }^{8}$ El mismo Habermas, cabría apuntar, se hace consciente de esta debilidad del elemento jurídico de integración exento de una activa cultura política como se comprobaría si se compara su evolución desde Faktizität und Geltung (1992) a sus trabajos posteriores como por ejemplo Die Einbeziehung des Anderen (1997).

${ }_{9}^{9}$ J. Habermas, El occidente escindido, op. cit., pp. 49-50.
} 
se da en ese nivel no implica una puesta en cuestión de la pervivencia de los otros planos y de otras lealtades ${ }^{10}$.

Ha sido sobre el trasfondo negativo de los conflictos de religión, de las contraposiciones entre poder eclesiástico y poder civil, entre ciudad y campo, entre las distintas culturas y los violentos enfrentamientos entre los Estados nacionales, que Europa ha terminado por establecer un juego ritual y de instituciones capaz de resolver y encauzar las disensiones, hacer que puedan mantenerse sin daños graves a las comunidades. Europa ha tenido que aprender a descentrar perspectivas, y desarrollar una actitud reflexiva respecto de los puntos ciegos sobre sí y sobre su mismo universalismo. Ha tenido que aprender dolorosamente de un pasado totalitario y también de su valerosa resistencia al mismo, de sus dos guerras mundiales, de los imperios fenecidos, y un largo etc. sin el que no se comprende su cultura política actual. Está en lo cierto a este respecto Habermas cuando afirma: "El núcleo de la identidad europea lo constituye, sin duda, más el carácter de los procesos de aprendizaje dentro de ella que su resultado"11.

La recurrente objeción, sostenida particularmente por los euroescépticos y nostálgicos de todo tipo, de una idealizada soberanía nacional, de que no existe un démos europeo, y que sin ello no puede haber nada de lo anterior, esfera pública europea ni ciudadanía, acostumbra a esgrimir paradójicamente una concepción pre-política, naturalista de démos, en las claves de un sujeto ya dado antes de toda organización o práctica, definido por una lengua, tradición, historia y manifestaciones artísticas que suelen perderse en la misma noche milenaria de la geografía por la que se sienten no menos constituidos. Se olvida que no hay sujeto político que no sea construcción, que no se constituya en la praxis, y que lo que aparece a menudo como dado no es sino coágulo del flujo de acción de otros momentos. A la tesis de la inexistencia de un "pueblo europeo" habría que recordarle que esos pueblos tan bien definidos de los que se reclama, no poco ilusoriamente, pues mucho tienen de comunidad imaginada (B. Anderson), también se han conformado en las luchas; que aquellas identidades de los pueblos nacionales se construyeron a través de procesos más o menos lentos, mediante una cultura política que implicaba un esfuerzo de abstracción respecto de los anteriores lazos de pertenencia, vínculos locales, y en el que la historiografía, los medios de comunicación de masas, el servicio militar obligatorio, las confrontaciones sociales, partidos, etc. jugaron un papel primordial ${ }^{12}$. En aquellas concepciones

\footnotetext{
${ }^{10}$ D. Tarizzo, sin embargo, considera que la integración solo podría darse en el nivel de la eticidad (Sittlichkeit), ligando a ésta la categoría de soberanía, y piensa que sus rasgos corren peligro con otro tipo de establecimiento de lealtades. Que solo un lento proceso de homogeneización, de articulación de eticidades constituiría el sujeto (pueblo europeo) que una unidad política superior exigiría.

${ }^{11}$ J. Habermas, “¿Necesita Europa una Constitución?” (2001), en Tiempo de transiciones, trad. de R. de Agapito, Madrid, Trotta, 2004, p. 132.

12 J. Habermas, "Euroescepticismo, Europa de los mercados o Europa de los ciudadanos (del mundo)" (1999), en Tiempo de transiciones, op. cit., p. 108. Ni que decir tiene que la posición de D. Tarizzo está
} 
naturalizantes el factor político se deja en un borroso trasfondo, y aparece un sujeto definido por el elemento nacional que se sobrepone al republicano ${ }^{13}$. El ciudadano se constituye, en realidad, en el proceso democrático mismo y la nueva solidaridad que genera en una comunidad ampliada, más abstracta obedece a mecanismos artificiales. Esa es la lección que debiera extraerse para la nueva proyección transnacional de aquella creada solidaridad. Son los procesos de aprendizaje, elementos que hoy tienen un alto carácter formal, a los que apuntábamos más arriba, los que perfilan el sujeto político europeo. Y no solo es inútil sino contraproducente para la nueva construcción europea alimentar la idea de un macrosujeto al modo como lo fabuló el metarrelato de la identidad, o de como se percibieron a sí los pueblos del XIX europeo $^{14}$.

En una línea semejante, de primacía del elemento político, habría que situar el enfoque de Balibar en que el sujeto político se deslinda del vínculo comunitarista con el que suele entenderse el concepto de démos, y en el contexto de lo que denomina cosmopolítica - más que cosmopolitismo- nos propone la idea de una "ciudadanía sin comunidad" o incluso de una "democracia sin demos", esto es, de una política transnacional -no postnacional-que toma formas nuevas no cortadas por las categorías propias del Estado nación ${ }^{15}$.

El periodo constituyente que se abrió con el debate del proyecto de Constitución fue sin duda una oportunidad más para contribuir a la emergencia de alguna de estas condiciones, pero la oportunidad no fue aprovechada, las mismas deficiencias apuntadas (esfera pública, ciudadanía, etc.), la conducción de las élites de Bruselas, la forma de elaboración del proyecto, además de su escaso atractivo, por su corte neoliberal, para no entrar en la dificultad de su enrevesado texto, que lo alejaba necesariamente de las gentes, hicieron que apenas se debatiera entre la población. El fracaso posterior, claramente anunciado por el proyecto político que se alejaba de eso que antes esbozamos como lo distintivo del modelo europeo, condujo a una parálisis de la que aún no hemos salido a pesar de los acuerdos posteriores.

3. La crisis económica actual no solo ha puesto de relieve los defectos de construcción de la UE sino que ha acentuado todos los elementos reactivos. Entre los primeros, ha quedado patente la unidimensionalidad de una moneda única sin acom-

\footnotetext{
muy lejos de la que aquí destacamos críticamente; y al respecto es de todo punto subrayable su importante distinción entre espacio político y cuerpo político.

${ }^{13}$ Justamente ese lazo es el que, como nos recuerda la punzante cita con la que D. Tarizzo encabeza su trabajo, el primer T. Mann no creía desanudable, el existente entre Democracia y nacionalismo.

${ }^{14}$ En ello lleva razón W. Müller, no es tampoco esa fabricación de grandes relatos lo que se reclamaría de los intelectuales europeos; J.-W. Müller, "The failure of European intellectuals?", en Eurozine, 4-11-2012.

${ }^{15}$ E. Balibar, "Strangers as enemies. Further Reflections on the Aporias of Transnational Citizenship", en Globalization Working Paper, May 2006: http://www.momaster.ca
} 
pañamiento de otras medidas de armonización fiscal y cobertura social, así como la clamorosa falta de operatividad del Banco Central Europeo. No se puede dejar a los países miembros sin el recurso de operar sobre sus monedas (establecimiento de tipos de cambio, devaluación, emisión de moneda) y a la vez limitar la actuación del BCE. El problema es que una vez dado los pasos hacia una integración mayor de los Estados, con la pérdida por parte de éstos de algunas de sus importantes atribuciones, sólo cabe avanzar lo más rápido posible hacia una armonización de los espacios económicos, de lo contrario las tensiones entre unas economías y otras resquebrajarán todo lo logrado. La posición intermedia es, como anotamos, la peor de todas para hacer frente a la situación en la que se está: sin los recursos del Estado nacional, pero tampoco sin los de una estructura competente de carácter superior, y con el problema añadido del conflicto interno generado por esa misma situación.

Cada paso en la des-regulación ha significado una merma paralela de la capacidad política, de autogobierno de la sociedad. En el diseño de la UE, especialmente a partir del Acta Única de 1986, se han desacoplado los planos del mercado de los del trabajo y las cuestiones sociales; se legisló sobre todo para abrir camino a aquel y responder a sus imperativos, y respecto a este segundo plano poco serio se hizo, con lo que se le venía a dejar a expensas del primero, a su mercantilización ${ }^{16}$. Así vemos cómo se ha institucionalizado un Banco Central cuyo único objetivo fijado, debido a la determinante influencia alemana, es la estabilidad de precios al margen de cualquier consideración de índole social. Éste ha sido uno de los golpes mayores a la capacidad de acción política, pues de este modo los Estados quedaban expuestos totalmente a los mercados, se limitaba extraordinariamente su capacidad para financiar sus costes sociales. Desde ese momento quedaban a expensas de los mercados financieros para cubrir sus políticas, y estos, en consecuencia, podían vetar tal o cual línea de actuación. Por mucho que se hablara al inicio de la crisis, con el hundimiento de los que se creían too big to fail, de un necesario retorno a Keynes, casi no lo recordamos, el hecho es que en las condiciones mencionadas una política keynesiana se hace imposible.

Ante la desastrosa situación generada, con el euro puesto en cuestión, Grecia al borde de la salida de la Unión, y otros Estados como Portugal, España e Italia aproximándose al abismo, el maximalismo de algunos se tuvo que relajar, y si bien en un principio el BCE no podía prestar dinero a los Estados, pudo permitirse mediante el estatuido "Mecanismo Europeo de Estabilización", luego institucionalizado en un formato de carácter secretista (MEDE) ${ }^{17}$, con la contrapartida letal de obligar a los deudores a someterse a los planes de ajuste marcados por las autoridades europeas.

\footnotetext{
${ }^{16}$ C. Joerges, "Europe's Economic Constitution In Crisis", en Zentra Working Papers in Transnational Studies 6, 2012, p. 7 y ss. Joerges toma como guía un principio teórico de K. Polanyi, para quien moneda, trabajo y tierra eran "mercancías ficticias".

${ }^{17}$ Ver E. Araujo, op. cit., p. 34.
} 
Se seguía así la desastrosa política económica que el FMI y el BM emplearon en su momento en Sudamérica, tan denunciada por los expertos no sujetos a votos de obediencia y por los líderes de aquellos países. Aun hace poco, en su visita a España, la combativa presidenta del Brasil, Dylma Roussell, recordaba a los europeos cómo ellos solo pudieron remontar la crisis cuando se sustrajeron a aquellos planes. Esa línea neoliberal impuesta a sangre y fuego es lo que obligó al gobierno Zapatero a una iniciativa que dejó a todos sus seguidores estupefactos, la de incluir los criterios neoliberales en la misma Constitución con la obligada limitación de un déficit presupuestario ajustado al mandato de la Unión Europea, que en estos momentos es el del 3\% del PIB.

Si Europa hoy viene simbolizada ante las gentes de los países con menos recursos no por el modelo de derechos del que arriba hablábamos sino por lo que representa la troika negriforme que inspecciona el cumplimiento de las políticas de recortes sociales nada podrá ya esperarse; las fuerzas centrífugas se incrementarán. Y el regreso a las políticas de pactos intergubernamentales con las consiguientes imposiciones de los fuertes sobre los débiles serán la tónica dominante. Habermas, nada proclive a extremismos, ha calificado la situación de federalismo ejecutivo post-democrático ${ }^{18}$. Alemania ha aprovechado la ocasión para replegarse a un política de Estado nación, de anteposición de intereses particulares inmediatos, en ruptura con una línea de conversión a Europa que tanto le ha costado en su historia reciente. El ideal de una Alemania europea parece sustituido ahora por una Europa alemana, mas dispuesta a satisfacer a la corriente, que sopla desde la reunificación, de una Alemania más segura de sí, que se deshace de sus auto-frenos, para imponerse en el concierto internaciona $1^{19}$. En este estado de cosas, no es difícil evocar alguna de las tesis de Carl $\mathrm{Schmitt}^{20}$, al menos su idea, en el contexto de la teoría del Grossraum, de que en una situación determinada que lo urgiera el poder ejecutivo de un país estaba legitimado para tomar medidas en ruptura con el marco del derecho internacional, revelando, claro es, quien ostentaba la verdadera soberanía. Algo de eso se viene a la mente en la actual situación, cuando vemos qué intereses son los dominantes tras las directrices de Bruselas.

El deterioro de la vida pública en los diversos países miembros, especialmente aquellos que sufren más dura y desprotegidamente la crisis es evidente. La crisis representa un zarpazo más a los lazos de cohesión social ya de por sí amenazados particularmente desde la caída del muro, y el desencadenamiento de las políticas neoliberales de la época Thacher-Reagan. El mercado arrasa en sucesivas oleadas

\footnotetext{
${ }^{18}$ J. Habermas, "Bringing the Integration of Citizens into Line with the Integration of States", en European Law Journal 18, 2012, pp. 485-488, aquí p. 487. Cfr. también J. Habermas, The Crisis of the European Union. A Response, Cambridge, Polity, 2012, p. 12 y ss., y p. 52.

${ }^{19}$ J. Habermas, The Crisis of the European Union, op. cit., p. 133.

${ }^{20}$ C. Joerges, op. cit., p. 19 y ss.
} 
cualquier otro vínculo que no sea el desnudo interés dejando a las gentes unas frente a otras en una lucha feroz por la asignación de recursos. Es significativo al respecto que para el portavoz del Deutsche Bank ya no se aprecie diferencia alguna entre las dimensiones política y económica: "En el marco de la integración de los espacios económicos [se refiere a la Unión europea] acaba por diluirse la vieja diferencia entre actividad ciudadana y económica" ${ }^{21}$.

Se redobla, entonces, el impulso hacia un repliegue localista, no sin los habituales componentes de etnocentrismo y xenofobia, en el que aun laten estratos más hondos como el rechazo de la complejidad de las sociedades modernas. Forma parte de ese repliegue algo que requeriría un análisis pormenorizado, como son las nuevas formas de impolítica como las que encarna la culturización de lo político, o el refugio en formas más primitivas de asociación (religión, nacionalismos primarios), en fin, un proceso inútil y costoso de re-encantamiento del mundo.

4. Más allá de las deficiencias señaladas, estructurales o de construcción, la cuestión hoy es que el avance en la unión, solo puede darse en el ámbito de una fuerte política social, en el horizonte de una alternativa cohesionadora ante la crisis. El avance hacia cualquier nuevo tipo de federalismo europeo, apoyado en los principios ya recogidos de combinación del doble sujeto, los ciudadanos y los pueblos, no podrá hacerse con cualquier política económica ${ }^{22}$. La orientación neoliberal actual con su consiguiente desintegración social alimenta la fragmentación política, y en muchos casos el repliegue desesperado en una ilusoria creencia en la posibilidad de resistir solos desde los resortes de un socavado Estado nacional. Con todo, la confianza persistente en esa figura política no es sino signo del valor que ha acabado representando, el de una fuerza civilizatoria, pacificadora y protectora en su traducción democrática y social. Eso mismo es lo que se esperaría que pudiera prometer la nueva construcción política en el selvático espacio internacional tanto con respecto al conflicto de intereses entre los distintos países y potencias como con respecto a las desbocadas fuerzas del mercado. Lo que no se está dispuesto de ninguna manera es a que se levante una estructura administrativa y de poder transnacional, mera acompañante del libre desenvolvimiento económico, que de nuevo haya que tratar de domesticar y poner al servicio de los ciudadanos, como se hizo, a través de sa-

\footnotetext{
${ }^{21}$ Tomo la cita de Habermas, "Euroescepticismo...", op. cit., p. 106.

${ }^{22}$ El desaparecido John Rawls expresaba en carta a Van Parijs su temor a que la UE caminase hacia una Eurofederación del tipo de la americana, en que los imperativos del mercado reducen a los ciudadanos a la condición de meros consumidores. No cabe duda de que esa posibilidad existe, pero no depende tanto de la estructura de federación, como de las políticas que se emplean. En lo que cada vez caben menos dudas es que en cuanto a la construcción política del futuro de la UE no parecen que quepan tantas posibilidades. Van Parijs, que no compartía el temor de Rawls, al menos su etiología, defendía precisamente un avance hacia una federación de tipo americano aunque con algunas diferencias. Ver Ph. Van Parijs, “A quasi-American strategy for European egalitarians”, en Green European Journal 20/12/2012.
} 
crificadas luchas de siglos, con el Leviatán doméstico. Los referendos perdidos, en el momento del proyecto de Constitución, señalaron algo ya al respecto. No cabe, pues, avance en la construcción de Europa si se persiste en la actual política de salida de la crisis, y no lo habrá de ningún modo si Europa, en el imaginario popular deja de simbolizar un determinado modelo político-social, ese que se ha perfilado justamente desde el final del último enfrentamiento bélico general entre europeos, y que la posterior guerra fría no dejó de impulsar. Nadie estará de grado dispuesto a contraer un nuevo contrato que caiga por detrás del que en su momento contrajo, aun cuando vea que este ya no pueda prestar los rendimientos de antaño. En ese impasse maquiaveliano estamos. Lo que se ofrece como futuro no convence, retroceder no es deseable y el inmovilismo es absolutamente destructivo. 